\title{
MULTIPLE GENETIC ALTERATIONS IN DISTAL AND PROXIMAL COLORECTAL CANCER
}
O. DELATTRE
D. J. LAW ${ }^{1}$
Y. REMVIKOS
X. SASTRE
A. P. FEINBERG ${ }^{1}$
S. OLSCHWANG
R. J. SALMON
P. VALIDIRE
G. THOMAS

Curie Institute, 75231 Paris Cédex 05, France; and Howard Hughes Medical Institute, and Departments of Internal Medicine and Human Genetics, University of Michigan Medical School, Ann Arbor, Michigan US $A^{1}$

Summary Multiple genetic alterations were changes in DNA content, mutations in ras oncogenes, and deletions involving chromosomes 5, 17, and 18. A nonrandom association of deletions and mitotic abnormalities by site was seen, with both types of alterations occurring significantly more frequently in distal tumours. In contrast, the frequency of c-Ki-ras mutations did not differ between proximal and distal cancers. In addition, deletions were significantly associated with each other and with change in DNA content. The data provide strong support for the hypothesis that proximal and distal colon carcinoma might differ in the genetic mechanisms in their initiation and/or progression.

\section{Introduction}

MANY genetic changes have been described in human cancer, often in the same type of tumour or even a specific tumour. Yet their order of occurrence during cancer initiation or progression, or the relation, if any, among them, are largely unknown. With a well characterised set of genetic alterations that are progressively gained during tumour development, colorectal cancer may provide a model to investigate these relations. These genetic alterations in colorectal cancer are of three general types. The first is a change in the DNA content of the malignant cells which can be monitored by flow cytometry. ${ }^{12}$ The second is specific loss of genetic material-ie, a complete loss of chromosome 18 and a structural re-arrangement of chromosome 17 leading most often to the loss of one short arm..$^{3-5}$ Since the gene for familial adenomatous polyposis coli, a dominantly inherited disorder predisposing to multiple premalignant adenomas was mapped to the long arm of chromosome 5, we and others have monitored the loss of this third chromosomal segment. By use of restriction fragment length polymorphisms (RFLPs) alleles on $5 \mathrm{q}$ proved to be lost in about a third of carcinomas..$^{5,6,8-10}$ This frequency is low, especially when compared with the frequency of allelic loss on chromosomes $17 \mathrm{p}$ and 18.5,6 The third type of genetic alteration, which occurs in nearly $40 \%$ of tumours, is the activation by point mutation of ras cellular oncogenes. ${ }^{6,11,12}$ This activation has never been shown for c-Ha-ras, rarely for N-ras, and most frequently for c-Ki-ras. In c-Ki-ras, with one exception, ${ }^{6}$ the activation always occurred by a change in the coding properties of the 12th or the 13th codon. Allelic deletions and c-Ki-ras mutations are occasionally present in adenomatous polyps, where they accumulate during tumour progression. Their frequency is greatest in carcinomas, where usually several different genetic alterations coexist. ${ }^{5,6}$
By examination of a large number of patients for each type of alteration-including losses of genetic material on chromosomes 5, 17, and 18, mutation of c-Ki-ras, and change in DNA content-we have been able to test directly for the possible relation between each of these changes, and tumour location.

\section{Patients and Methods}

Fresh tissue was obtained from patients referred to the Curie Institute, the Johns Hopkins Hospital, the University of Michigan Hospital, the Roswell Park Memorial Institute, and the Cleveland Clinic, from 1981 to 1988 . The tumours were classified according to anatomical subgroups: proximal (from caecum to splenic flexure), distal (from splenic flexure to end of sigmoid), and rectal. Subgroups of tumours classified according to modified Dukes' stage $^{13}$ did not differ significantly with respect to tumour site. 12 tumours came from hepatic metastases. Our series is representative of the colorectal carcinomas found in western countries with respect to site of tumour, age of patients at diagnosis, and staging. However, $60 \%$ of the total tumours studied were from female patients. Gender does not seem to affect distribution of cancer by site or Dukes' stage. ${ }^{14}$ This observation was confirmed in this work, and in addition no heterogeneity was observed between sexes with respect to the occurrence of genetic alterations. We have excluded carcinomas that occurred in patients with adenomatous polyposis coli.

DNA in all but 20 tumours was extracted from surgical specimens, which were cryostat-sectioned. ${ }^{5}$ In 5 patients, the tumour DNA was extracted from flow-sorted hyperploid nuclei, and in 15 patients from the first or second passage of tumours grafted on nude mice. In the 9 patients in whom we could compare the karyotype of the primary tumour with that of its grafted homologue, only minor variations, which did not affect chromosome 5,17 , or 18 , were seen ${ }^{15}$. The probes used (and their chromosomal location) were: YNZ22 (17p13.3), YNH37.3 (17p13.3), D17S1 (17p13), MYH2 (17p13.1), OLVIIA8 (18q11), OLVIIE10 (18q21.3), OS-4 (18q21.3-qter), B74 (18p11.3), C11P11 (5q21-22), CRI-L1265 (5q21-22), CRI-L372 (5q21-22), CRI-L379 (5q21-22). ${ }^{16}$ Partial data on 35 of the 119 informative patients have been reported..$^{45}$ Allelic typing of constitutional and tumour DNA was done with slight modifications of Southern's technique. ${ }^{4}$

C-Ki-ras mutations were investigated on DNA amplified with the Taq polymerase according to Bos and colleagues' method ${ }^{11}$ with the same amplimers. Mutations were identified by sequential hybridisation to 12 oligonucleotides, each specific for one of the twelve possible single point mutations that would substitute glycine at the 12th and 13th position of the peptide sequence.

Flow cytometry was done on 138 carcinomas as previously described. ${ }^{17}$ The ratio of the DNA content of malignant cells to that of normal cells is termed the DNA index of the tumour (n). The distribution of $n$ is bimodal, with one population centred on $n=1$ and the other more widely distributed around $n=1.6$ (figure).

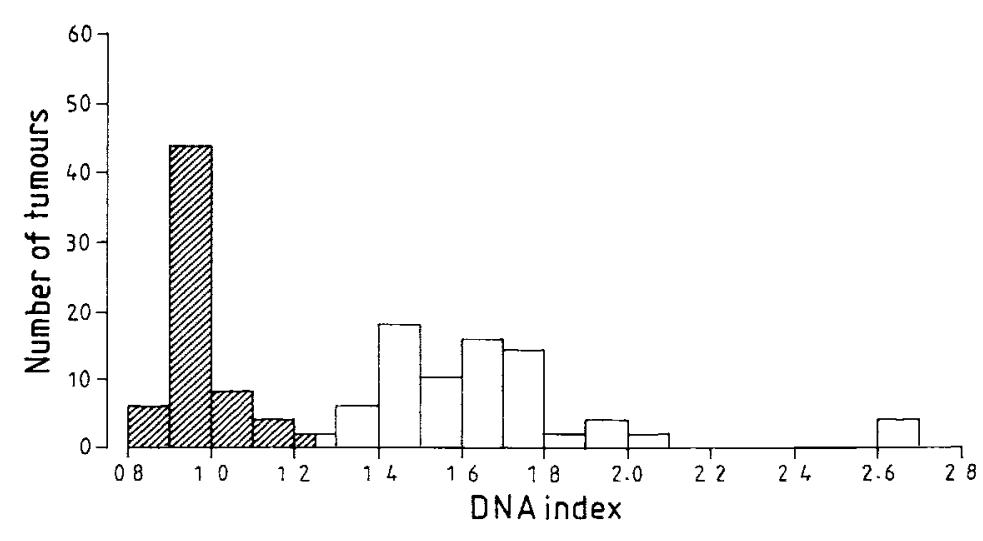

Distribution of 138 carcinomas according to DNA index.

$\square$, paradiploid tumours; $\square$, hyperploid tumours. 
TABLE I-FREQUENCY OF GENETIC AITERATIONS ACCORDING TO SITE OF TUMOUR*

\begin{tabular}{l|c|c|c|c}
\hline \multicolumn{1}{c|}{} & $\begin{array}{c}\text { Proximal } \\
\text { colon }\end{array}$ & $\begin{array}{c}\text { Distal } \\
\text { colon }\end{array}$ & Rectum & p valuet \\
\hline Allelic loss & $58 \%(19)$ & $3 \%(37)$ & $14 \%(22)$ & $<0.001$ \\
None & $30 \%(23)$ & $74 \%(50)$ & $74 \%(27)$ & $<0.001$ \\
On 17p & $30 \%(23)$ & $85 \%(48)$ & $64 \%(28)$ & $<0.001$ \\
On 18 & $11 \%(19)$ & $45 \%(40)$ & $41 \%(27)$ & $<005$ \\
On 5q & $20 \%(20)$ & $66 \%(58)$ & $56 \%(41)$ & $<0.005$ \\
Hyperdiplondy & $41 \%(29)$ & $31 \%(61)$ & $54 \%(39)$ & NS \\
\hline -K2-ras mutation & $41 \%$ \\
\hline
\end{tabular}

*Number of informative tumours from which percentages derived shown in parentheses.

tFor all 3 locations.

$\mathrm{NS}=\mathrm{p}>0.05$

These populations are called paradiploid (n less than 1.3) and hyperploid (n greater than or equal to 1.3), respectively. When two proliferating clones with different DNA indices were observed in the same tumour, the larger DNA index was used. Cancerous cells having an exactly diploid content of DNA were monitored by the presence on the flow cytogram of an S-phase cell population and an exactly tetraploid G2-phase cell population which were never seen in preparations from non-cancerous fragments of colorectal mucosae.

Two by tv, 3 tables were analysed by the chi-squared test with Yates' correction. Multiple regression analysis was also done.

\section{Results}

\section{Allelic Losses and Hyperploidy}

A set of 12 probes detecting RFLPs on the short arm of chromosome 17 , the long arm of chromosome 5 , and both arms of chromosome 18 was used to monitor allelic losses. Allelic losses on chromosome $17 \mathrm{p}$ ( 71 lost of 113 informative patients; $63 \%$ ) and $18(66$ of $107 ; 62 \%$ ) were seen more frequently than those on chromosome $5 \mathrm{q}$ ( 38 of $98 ; 39 \%$ ). These frequencies are in agreement with published data. ${ }^{6} \mathrm{~A}$ total of 95 carcinomas demonstrated at least one allelic loss. However, 24 carcinomas, among which 15 were informative for all three non-syntenic chomosomal regions tested, did not show any loss of alleles. Of these, 3 tumours were successfully grafted on nude mice. Their xenografts, which were completely devoid of non-cancerous human cells, did not show loss of alleles for loci on $17 \mathrm{p}, 18$, and $5 \mathrm{q}$. When we compared the frequency of allelic loss with site of the tumour within the colon, the differences were striking. Allelic losses on all three chromosomes were more than twice as frequent

TABLE II-SINGLE-BASE MUTATIONS IN 12TH AND 13TH CODON OF C-Ki ras IN 152 COLORECTAL CARCINOMAS

\begin{tabular}{l|c|c|c|c}
\hline \multirow{2}{*}{} & \multicolumn{4}{|c}{ Codon no } \\
\cline { 2 - 5 } & 11 & 12 & 13 & 14 \\
\hline $\begin{array}{c}\text { Sequence of } \\
\text { c-Ki-ras }\end{array}$ & GCT & G G T & G GC & G T A \\
\hline
\end{tabular}

$\star$ Position of Gs $(1-4)$ that can be mutated in activated c-Ki-ras.

\begin{tabular}{|c|c|c|c|c|}
\hline & & \multicolumn{3}{|c|}{ G mutated tot } \\
\hline \multicolumn{2}{|c|}{ 一 } & A & $\mathrm{T}$ & $\mathrm{C}$ \\
\hline \multirow{3}{*}{$\begin{array}{l}\text { Mutated base } \\
\text { 12th codon }\end{array}$} & & & & \\
\hline & $\mathrm{G} 1$ & 2 (Ser) & 7 (Cys) & 2 (Arg) \\
\hline & $\mathrm{G} 2$ & 17 (Asp) & 18 (Val) & 4 (Ala) \\
\hline \multirow[t]{2}{*}{ 13th codon } & G3 & $O$ (Ser) & 2 (Cys) & 0 (Arg) \\
\hline & G4 & 11 (Asp) & 0 (Val) & 0 (Ala) \\
\hline
\end{tabular}

t63 mutations shown.

Aminoacids replacing glycine shown in parentheses.
TABLE IIL-RELATION BETWEEN HYPERPLOIDY AND ALLELIC LOSSES ON CHROMOSOMES $17 \mathrm{p}, 18$, AND $5 \mathrm{q}^{\star}$

\begin{tabular}{c|c}
\hline- & Frequency of hyperploid tumours \\
\hline Loss on $17 p / 18:$ & \\
No/no & $5 \%(19)$ \\
Yes/no & $64 \%(11)$ \\
No/yes & $60 \%(10)$ \\
Yes/yes & $69 \%(45)$ \\
Loss on 5q/17p: & \\
No/no & $0 \%(12)$ \\
Yes/no & $40 \%(5)$ \\
No/yes & $73 \%(26)$ \\
Yes/yes & $54 \%(24)$ \\
Loss on $5 q / 18:$ & \\
No/no & $22 \%(18)$ \\
Yes/no & $40 \%(5)$ \\
No/yes & $75 \%(28)$ \\
Yes/yes & $61 \%(23)$ \\
\hline
\end{tabular}

No of informative tumours from which percentages derived shown in parentheses.

in distal tumours than in proximal tumours (table I). There were similar pronounced variations in the frequency of hyperploidy in distal tumours compared with proximal tumours (table I).

These differences in frequency of genetic alteration by tumour location did not include mutation in c-Ki-ras (table I). The systematic screening of 152 colorectal adenocarcinomas for possible single point mutations on codon 12 and 13 that could alter the structure of the c-Ki-ras protein (table II) enabled the following obsrvations. Each possible mutation for codon 12 was found. The mutations involved more frequently the second $G$ of each codon (which is $5^{\prime}$ flanked by a purine) than the first (which is $5^{\prime}$ flanked by a pyrimidine). Also $\mathrm{G}$ to $A$ transitions and $\mathrm{G}$ to $\mathrm{T}$ transversions occurred at greater frequency than $G$ to $C$ transversions. This mutation pattern is similar to that induced by alkylating agents. Finally, the substitution Gly 13 for Val13 which is obtained by a $G$ to $T$ mutation on the second base of the codon was not found, suggesting that this substitution does not activate c-Ki-ras.

\section{Inter-relation Among Genetic Alterations}

One of the most important questions raised by the presence of multiple genetic alterations in tumours is, are they related to one another or do they occur independently? To address this question we analysed the frequency of each genetic change in a two by two comparison with every other genetic change in all tumours informative for at least two non-syntenic loci. When we compared allelic losses on chromosome $17 \mathrm{p}$ and chromosome 18 there was an easily noticeable and highly significant association: 12 of 36 tumours had an allelic loss on $17 \mathrm{p}$ but not on 18 , and 53 of 66 had a loss on both chromosomes $(p<0.001)$. In the other comparisons 33 of 60 showed a loss on $17 \mathrm{p}$ but not on $5 \mathrm{q}$, and 26 of 32 showed a loss on both $(p<0.02) ; 36$ of 60 had a loss on 18 but not on $5 \mathrm{q}$, and 26 of 32 showed a loss on both $(p<0.05)$. We concluded that loss of alleles on any of the three investigated chromosomal segments increased the probability of finding a loss of heterozygosity on the other two. This non-random association of allelic loss was still very striking when the analysis was done in the subgroups of proximal tumours (data not shown).

The percentage of hyperploid tumours was examined in groups classified according to various two by two combinations of allelic losses. Table III shows that in any 
group of tumours having lost alleles on either $17 \mathrm{p}$ or 18 the percentage of hyperploid tumours is strikingly increased. The relation between loss of chromosome 5 alleles and ploidy seemed less close. The rare tumours (in only 3 patients) that had lost alleles on chromosome 5 while keeping all informative heterozygosities on $17 \mathrm{p}$ and 18 were paradiploid. These observations indicate that loss of alleles on $17 \mathrm{p}$ or on 18 might be implicated in the generation of hyperploidy.

\section{Discussion}

We have shown two apparently mechanistically unrelated classes of genetic alterations. One class consists of localised alterations such as $\mathrm{c}-\mathrm{Ki}$-ras activation by point mutation. Its occurrence along the length of the colorectum was subject to only small variations. The second class, which seemed to occur independently of the first, produces large scale alterations such as loss of chromosomal segments or hyperploidy. As suggested by cytogenetic studies, this second class might be restricted to a subset of colorectal tumours. ${ }^{18}$ Its frequency is clearly dependent on tumour site. In our series this second class of alteration was detected in almost all distal colon tumours but only in slightly more than a third of the proximal colon tumours.

Different frequencies of genetic alterations in proximal and distal colon have several important implications. First the variations may explain, at least partly, the substantial difference in frequencies of genetic alteration reported by several workers..$^{5-9}$ Second, they strongly suggest a biological difference between proximal and distal tumours.

Three lines of evidence have suggested that tumours from the proximal colon might differ both in their initiation and in their evolution from those in the rest of the colorectum. Epidemiological studies in western countries have lately shown an increase in the frequency of the proximal tumours compared with that of distal tumours. ${ }^{19-21}$ This difference does not seem to be attributable to improved diagnostic techniques. ${ }^{21}$ In addition, significant differences were seen in the relative frequency of proximal and distal tumours in various populations. ${ }^{22}$ Second, family studies have suggested that various genes might be implicated in colorectal carcinogenesis. In familial polyposis patients, numerous adenomatous polyps usually occur and degenerate to carcinoma in the distal part of the colorectum. $^{23}$ In hereditary non-polyposis colorectal cancers (Lynch syndromes) most tumours appear in the proximal colon and are not preceded by the development of multiple polyps. ${ }^{24}$ Third, proximal and distal tumours show differences in the expression of cellular oncogene such as c-myc. ${ }^{25}$

One of the challenges in investigations of multiple acquired genetic alterations during carcinogenesis is to relate them pathophysiologically. The high frequency of allelic losses on $17 \mathrm{p}$ and 18 in hyperploid tumours argues strongly in favour of the hypothesis that most of the hyperploid tumours result from the clonal proliferation of a cell in which loss of chromosomal segments had taken place before or during the endomitosis leading to hyperploidy. Indeed, on simple mathematical grounds, loss of heterozygosity would be more easily achieved when the tumour cells are paradiploid (in which case only one loss of a chromosomal segment is needed), than when the tumour cells would need to delete several homologous chromosomes of the same parental origin to achieve loss of heterozygosity. It can be speculated that tumours which have lost chromosomal segments are achieving functional nullizygosity for tumour suppressor genes. However, as a result of this deletion, they might also become hemizygous for one or more growth promoting genes on the same chromosomal arm. Hemizygous expression of these growth promoting genes might restrict the cells' growth potential. The cancer cell would thus be expected to obtain a selective advantage from an endomitosis which, in one step, would restore two copies per cell for these growth promoting genes and might provide through the reconstitution of a reserve of DNA more flexibility for further genetic rearrangements in subsequent tumour progression.

Several models could take into account the multiple association of allelic losses in tumour cells. They might represent genetic instability that predisposes to multiple genetic alterations. This hypothesis was first proposed by Boveri $^{26}$ and in more modern form by Nowell. ${ }^{27}$ This instability might be an acquired and persistent property of a class of cancer cells that would progressively gain a number of genetic alterations. It is possible, however, that this instability is only transiently expressed. For instance, several allelic losses could take place in the course of a single aberrant mitosis in cells which, before or after this mitosis, would not be genetically unstable. An alternative hypothesis is that the growth advantage of multiple allelic losses may not be simply additive, but synergistic; thus one might be more likely to find tumours with multiple losses. In either case the association of multiple genetic alterations with each other and with a preferential location suggests distinct genetic mechanisms that may explain biological differences among tumours.

We thank Prof J. F. Lacronique, Dr J. M. Lhoste, and Dr B. Dutrillaux for continued interest and help; Dr G. Goubin for providing some of the oligonucleotides; Dr D. Jagelman and Dr N. Petrelli for providing some of the tumour samples; and Dr B. Wieffenbach, Dr R. White, Dr Y. Nakamura, and Dr B. Vogelstein for providing RFLP probes. This work was supported by grants from the Ligue Nationale Contre le Cancer (comite de Paris and axe de biologie moléculaire clinique) to $G$. T. and from Howard Hughes Medical Institute to A. P. F; O. D. is a recipient of a grant from the $\mathrm{LNCC}$ comité de lYonne.

Correspondence should be addressed to $G$. T.

\section{REFERENCES}

1. Geh HS, Jass JR, Atkin WS, Cusick J, Northover JMA. Value of flow cytometric determination of ploldy as a guide to prognosis in operable cancer. a multivariate analysis. Int $\mathcal{F}$ Colorect Dis 1987; 2: 17-21

2. Schutte $B$, Reynders MMJ, Wiggers $T$, et al. Retrospective analysis of the prognosis significance of DNA content and proliferatave activity in large bowel carcinoma. Cancer Res 1987; 47: 5494-96

3. Muleris M, Salmon RJ, Zafranı B, Girodet J, Dutrillaux B. Consistent deficiences of chromosome 18 and of the short arm of chromosome 17 in eleven cases of human large bowel cancer: a possible recessive determumsm. Ann Genet 1985; 28: 206-13.

4. Monpezat JP, Delattre O, Bernard A, et al. Loss of alleles on chromosome 18 and on the short arm of chromosome 17 in polyploid colorectal carcinomas. Int $\mathcal{f}$ Cancer 1988; 41: 404-08

5. Law DJ, Olschwang S, Monpezat JP, et al. Concerted nonsyntenic altelic loss in human colorectal carcinoma Scrence 1988; 241: 961-65.

6. Vogelstein B, Fearon ER, Hamilton SR, et al. Genetic alterations during colorectaltumor development. $N$ Engl f Med 1988; 319: 525-32.

7. Fearon ER, Hamiton SR, Vogelstein B. Clonal analysis of human colorectal tumours. Scrence 1987; 238: 193-97.

8. Solomon E, Voss R, Hall V, et al. Chromosome 5 allele loss in human colorectal carconomas. Nalure 1987; 328: 616-19.

9. Okamoto $M$, Sasaki $M$, Sugio $K$, et al. Loss of constitutional heterozygosity in colon carcinoma from patients with familial polyposis coll. Nature 1988; 331: 273-77.

10. Wildrick DM, Boman B. Chromosome 5 allele loss at the glucocortucoid receptor locus in human colorectal carcinomas. Biochem Biophys Res Commun 1988; 150: 591-98.

11. Bos JL, Fearon ER, Hamilton SR, et al. Prevalence of ras gene mutations in human colorectal cancer. Nature 1987; 327: 293-97.

12. Forrester K, Almoguera C, Han K, Grizzle WE, Perucho M. Detection of high incidence of K-ras oncogenes during human colon tumourigenesis. Nature 1987; 327: 298-303.

13. Dukes CE. Classification of cancer of the rectum. F Pathol Bacteriol 1932; 35: 323-32.

References continued at foot of next page 


\section{S-METHYLATION IN MOTORNEURON DISEASE AND PARKINSON'S DISEASE}

\author{
R. H. WARING \\ S. G. STURMAN \\ M. C. G. SMITH
}

\author{
G. B. STEVENTON \\ M. T. E. HEAFIELD \\ A. C. WILliams
}

\section{Departments of Biochemistry and Neurology, University of Birmingham, Birmingham}

Summary Thiolmethyltransferase activity has been measured in newly diagnosed, untreated patients with idiopathic Parkinson's disease and motorneuron disease, and in normal volunteers. In Parkinsonian patients, mean thiolmethyltransferase activity was low (300 U/mg protein [SD 96]) compared with that in controls (947 [409]), whereas activity was high in patients with motorneuron disease (2077 [825]).

\section{Introduction}

N-Methyl-4-phenyl-1,2,5,6-tetrahydropyridine (MPTP) selectively damages dopaminergic neurons in the substantia nigra, and causes symptoms and signs indistinguishable from idiopathic Parkinson's disease. ${ }^{1,2}$ We reported a patient with motorneuron disease that occurred acutely after exposure to a pesticide that contained pyrethroid derivatives and a fluorocarbon propellant. ${ }^{3}$ Could both these diseases-in which no vascular or inflammatory component has been found-be caused by chronic poisoning by a chemical in the environment?

In man, such chemicals, like drugs, are usually metabolised after absorption by the hepatic microsomal enzyme system to a water-soluble form that can be more easily excreted. A relative inability to increase the watersolubility of such a toxic compound could lead to accumulation of the toxin in neurons, because excretion by the kidneys would be impaired and movement across the blood-brain barrier facilitated. We have found that patients with Parkinson's disease and motorneuron disease have reduced capacity to form the S-oxides of S-carboxy-methylL-cysteine, ${ }^{4,5}$ but have a normal capacity for debrisoquine hydroxylation. ${ }^{6}$ In accordance with this observation, patients with Parkinson's disease and motorneuron disease form reduced amounts of sulphate conjugate when challenged with paracetamol. ${ }^{4,5}$ The enzyme cysteine dioxygenase is thought to be responsible for the sulphoxidation reaction, ${ }^{7}$ which converts cysteine to inorganic sulphate and is the rate-limiting step in the formation of sulphate conjugates. ${ }^{8}$ The enzyme thiolmethyltransferase [E.C. 2.1.1.9] is membrane- associated and catalyses S-methylation of various aliphatic sulphydryl compounds. There is a genetically determined variation in thiolmethyltransferase activity in a normal population.9,10 We have studied this enzyme in newly diagnosed and untreated patients with Parkinson's disease and motorneuron disease.

\section{Patients and Methods}

Unselected patients with newly diagnosed idiopathic Parkinson's disease ( $8 \mathrm{M}, 10 \mathrm{~F}$; age 61.7 years, range $41-76)$ were recruited after ethical committee approval and their own informed consent. None had been treated with an anticholinergic drug, levodopa, or a dopamine agonist, nor were they on any other medication. Patients with atypical clinical features or subsequent lack of response to levodopa were excluded, and all had at least two of the three cardinal features of resting tremor, rigidity, or bradykinesia.

Consecutive patients with newly diagnosed motorneuron disease were also studied (10M, 10F; age 63.1 years, range 52-82). Patients with atypical features, such as onset under 30 years of age, were excluded. These patients had clinical and electrophysiological features typical of motorneuron disease, were on no medication, and had all been investigated to exclude any alternative diagnosis such as cervical spondylosis or motor neuropathy. No patient who was bedridden or who had had to alter their diet to combat bulbar problems was included.

One control group consisted of normal volunteers $(10 \mathrm{M}, 10 \mathrm{~F}$; age 58.1 years, range 35-90), with no evidence of disease and on no medication. Patients with myasthenia gravis were used as a second group of hospital controls $(6 \mathrm{M}, 6 \mathrm{~F}$; age 51.9 years, range $16-78)$.

Venous blood samples $(10 \mathrm{ml})$ were taken and red blood cell membranes were prepared by the methods of Weinshilbaum et $\mathrm{al}^{9}$ and Keith et al. ${ }^{10}$ Thiolmethyltransferase activity was measured by modification of the method of Keith et $\mathbf{~}^{10}{ }^{10}$ based on the conversion of 2-mercaptoethanol to radiolabelled S-methylmercaptoethanol by thiolmethyltransferase; ${ }^{14} \mathrm{C}$-methyl-S-adenosyl-L-methionine was used as the methyl donor. Conversion of 2-mercaptoethanol to $S$-methylmercaptoethanol was also measured by high-performance liquid chromatography with ultraviolet detection without use of radioactive labels $(10 \mu \mathrm{l}$ injected, pressure $120 \mathrm{bar}$, mobile phase $5 \%$ methanol in water, flow rate $1.6 \mathrm{ml} / \mathrm{min}$, 'Teckopack 10 ' $5.0 \mu \mathrm{m}$, $250 \mathrm{~mm} \times 3.9 \mathrm{~mm}$ ID C18 column). The correlation of results by the two methods was found to be 0.98. Enzyme activity is expressed as $\mathrm{U} / \mathrm{mg}$ protein, and all results are shown as mean (SD). A two-tailed Student's $t$ test was used for statistical analysis. The assayist was unaware of the clinical diagnosis at the time of assay.

\section{Results}

The results obtained are shown in the figure. There was no significant difference in thiolmethyltransferase activity between the control groups of normal volunteers $(947 \mathrm{U} / \mathrm{mg}$ protein [409]) and patients with myasthenia gravis (883 $\mathrm{U} / \mathrm{mg}$ protein [319]). As previously observed, there was no difference seen between sexes and no variation with age, and

\section{O. DELATTRE AND OTHERS: REFERENCES-continued}

14. Eisenberg B, Decosse JJ, Harford F, Michalek J. Carcinoma of the colon and rectum: the natural history reviewed in 1704 patients. Cancer 1982; 49: 1131-34.

15. Lefrançois D, Olschwang $S$, Delattre $O$, et al. Preservation of chromosome and DNA characteristics of human colorectal adenocarcinomas after passage into nude mice. Int $\mathcal{F}$ Cancer (in press).

16. Kidd KK, Bowcock AM, Pearson PL, et al. Human gene mapping 9.5. Cytogenet Cell Genet 1988; 49: 132-218.

17. Remvikos $Y$, Muleris $M$, Vielh $P$, Salmon RJ, Dutrillaux B. DNA content and genetic evolution of human colorectal adenocarcinoma: a study by flow cytometry and cytogenetic analysis. Int f Cancer 1988; 42: 539-43.

18. Muleris M, Salmon RJ, Dutrillaux B. Existence of two distinct processes of chromosomal evolution in near-diploid colorectal tumors Cancer Genet Cytogenet 1988; 32: 43-50.

19. Snyder DN, Heston JF, Migs JW, Flannery JT. Changes in site distribution of colorectal carcinoma in Connecticut, 1940-1973. Dig Dis 1977; 22: 791-97.

\footnotetext{
20. Mamazza J, Gordon PH. The changing distribution of large intestinal cancer. Dis Col Rect 1982; 25: 558-62.

21. Beart RW, Melton LJ, Maruta M, Dockerty MB, Frydenberg HB, O'Fallon WM Trends in right and left-sided colon cancer. Dis Col Rect 1983; 26: 393-98.

22. Johnson H, Carstens R. Anatomical distribution of colonic carcinomas. Cancer 1986; 58: $997-1000$.

23. Bussey HJR. Famulial polyposis coli. Baltimore: Johns Hopkns University Press, 1975.

24. Lynch HT, Lynch JF. Genetics and colorectal cancer. In: Muller HJ, Weber W, eds. Basel: Karger, 1985: 72-77

25. Rothberg PG, Spanforder JM, Ensman MD, et al. Evidence that c-myc expression defines two generically distunct forms of colorectal carcinoma. Br $\mathcal{F}$ Cancer 1985; 52 $629-32$.

26. Boverı T. Zur Frage der entstehung maligner Tumoren. Jena: Gustav Fischer, 1914
} 27. Nowell P. The clonal evolution of tumor cell population. Science 1976, 194: 23-28 